\title{
The Comparison of Cracking Susceptibility of IN52M and IN52MSS Overlay Welds
}

\author{
Min-Yi Chen ${ }^{1}$, Tai-Jung Wu ${ }^{2}$, Tai-Cheng Chen ${ }^{2} \mathbb{C}$, Sheng-Long Jeng ${ }^{2} \mathbb{C}$ and Leu-Wen Tsay ${ }^{1, *} \mathbb{C}$ \\ 1 Institute of Materials Engineering, National Taiwan Ocean University, Keelung 20224, Taiwan; \\ stronac5102@gmail.com \\ 2 Division of Nuclear Fuels and Materials, Institute of Nuclear Energy Research, Taoyuan 32546, Taiwan; \\ gordon@iner.gov.tw (T.-J.W.); tcchen@iner.gov.tw (T.-C.C.); sljeng@iner.gov.tw (S.-L.J.) \\ * Correspondence: b0186@mail.ntou.edu.tw; Tel.: +886-2-2462-2192 (ext. 6405)
}

Received: 14 May 2019; Accepted: 1 June 2019; Published: 4 June 2019

\begin{abstract}
Overlay-welding of IN52M and IN52MSS onto CF8A stainless steel (SS) was conducted by a gas tungsten arc welding process in multiple passes. An electron probe micro-analyzer (EPMA) was applied to determine the distributions and chemical compositions of the grain boundary microconstituents, and the structures were identified by electron backscatter diffraction (EBSD). The hot cracking of the overlay welds was related to the microconstituents at the interdendritic boundaries. The formation of $\gamma$-intermetallic $\left(\mathrm{Ni}_{3}(\mathrm{Nb}, \mathrm{Mo})\right)$ eutectics was responsible predominantly for the hot cracking of the 52M and 52MSS overlays. The greater Nb and Mo contents in the 52MSS overlay enhanced the formation of coarser microconstituents in greater amounts at the interdendritic boundaries. Thus, the hot cracking sensitivity of the 52MSS overlay was higher than that of the 52M overlay. Moreover, migrated grain boundaries were observed in the 52M and 52MSS overlays but did not induce ductility dip cracking (DDC) in this study.
\end{abstract}

Keywords: IN52M; IN52MSS; weld overlay; hot cracking; ductility dip cracking; CF8A stainless steel

\section{Introduction}

Stress corrosion cracking (SCC) is a major concern in high temperature water environments, which are commonly found in water reactors and piping systems in nuclear power plants [1-4]. IN82/182 butt joints are used extensively for the joining of dissimilar welds, which have been found to suffer from SCC in nuclear power plants [1-4]. An alternative to applying a weld overlay onto the damaged components is performed instead of replacement [5]. IN52, 52M, and 152 alloys are widely used as the filler metals for the overlay-welding of different components to alleviate SCC damage in those dissimilar welds [6,7]. Induced compressive residual stress in the inner surface of the pipes is helpful to lower the SCC sensitivity after overlay-welding [8,9].

It is known that the Ni-based alloys are prone to hot cracking during welding [10-15]. The formation of low temperature liquid films and eutectic constituents at the solidified boundaries accounts for the occurrence of hot cracking of the Ni-based alloys [16,17]. It is reported that, among the distinct zones in a 52M overlay weld, the weld interface has the highest cracking tendency [18]. The hot cracking susceptibility of 52M overlay welds is strongly affected by contamination of impurity elements from the substrate during welding [19-22]. Decreasing the dilution rate of a dissimilar weld will be an effective way to mitigate hot cracking of 52M overlays $[19,20]$. In practical application, depositing proper buffer layers before a $52 \mathrm{M}$ overlay is applied decreases the number of hot cracks in the welds [21,22]. It is reported that for reducing hot crack sensitivity, a 307Si buffer layer is marginally better than a 308L one [23]. The enrichment of $\mathrm{Nb}$ at the interdendritic boundaries favors liquation cracking of 52M overlays [24]. Moreover, an increase in $\mathrm{Nb}$ and Mo contents increases the size and 
amount of interdendritic phases [25]. Coarse $(\mathrm{Nb}, \mathrm{Ti}) \mathrm{C}$ precipitates in $52 \mathrm{M}$ overlays will enhance the formation of Laves phases and increase their size $[25,26]$, leading to increased hot crack sensitivity of the overlay welds.

Besides the occurrence of hot cracking, Ni-based deposits for repair-welding of nuclear reactor components can be susceptible to ductility dip cracking (DDC) [27-29]. DDC in a Ni-based alloy weld mainly occurs in the reheated weld at elevated temperatures, and it is related to grain boundary (GB) sliding, impurity segregation at GBs, and intergranular precipitation [30]. GB sliding is responsible for the DDC of 52M deposits in strain-to-fracture tests [31]. Moreover, ductility dip cracks are initiated due to the combined effects of the strain concentration on the concave side of the grain boundary, the orientation of the GB to the loading direction, and GB disorientation [32]. In a prior study, IN52 alloy is reported to be more susceptible to DDC than IN82 alloy [33]. Adding Nb and Ti into IN52 alloy can reduce its DDC susceptibility due to the precipitation of $\mathrm{NbC}$ and $\mathrm{TiC}$ at the GBs [30]. It was reported that the DDC of a 52MSS weld, which was modified from $52 \mathrm{M}$ by adding $2.5 \% \mathrm{Nb}$ and $3.0 \% \mathrm{Mo}$, can be alleviated even after multi-pass welding $[34,35]$.

In this study, IN52M and IN52MSS fillers were employed to perform overlay-welding on CF8A SS substrate. The microstructures and chemical compositions of the microconstituents at the solidified boundaries of the overlay welds were investigated. The hot cracking tendency and DDC of 52M and 52MSS overlays were evaluated by inspecting the interior microfissures carefully. Grain boundary micro-constituents were analyzed by electron backscatter diffraction (EBSD) to identify the complex phases. Furthermore, the relationships between microstructural features and the cracking tendencies of the overlay welds were correlated with those interdendritic precipitates.

\section{Materials and Experimental Procedures}

CF8A, a centrifugal cast austenitic stainless steel (CASS), was machined into plate form with dimensions of $100 \mathrm{~mm} \mathrm{~L} \times 90 \mathrm{~mm} \mathrm{~W} \times 30 \mathrm{~mm}$ T as the substrate for overlay-welding. Gas tungsten-arc welding process in multi-passes was applied for the overlay-welding. In general, a SS buffer layer was deposited before the nickel-based filler metal was applied onto the CF8A substrate. In this study, ER (Electrode Rod) 308L filler of $1.2 \mathrm{~mm}$ diameter was deposited onto the CF8A substrate as the buffer layer. Alloy 52M and 52MSS fillers of $0.9 \mathrm{~mm}$ diameter were deposited either directly onto the CF8A substrate or onto the 308L buffer layer. The chemical compositions of the CF8A substrate, ER308L, 52M, and 52MSS fillers used in this work are listed in Table 1. The welding parameters used in this study were welding current of 185 amperes, welding voltage of 19.5 volts, and travel speed of $125 \mathrm{~mm} / \mathrm{min}$. The filler-feeding speed was changed to alter the deposition rate or effective heat input of the overlay-welding.

Table 1. The chemical compositions (in wt.\%) of the materials used in this work.

\begin{tabular}{ccccccccccccc}
\hline \multirow{2}{*}{ Materials } & \multicolumn{10}{c}{ Elements } \\
\cline { 2 - 12 } & $\mathbf{C}$ & $\mathbf{C r}$ & $\mathbf{N i}$ & $\mathbf{F e}$ & $\mathbf{M n}$ & $\mathbf{N b}$ & $\mathbf{M o}$ & $\mathbf{T i}$ & $\mathbf{S i}$ & $\mathbf{P}$ & $\mathbf{S}$ & $\mathbf{N b}+\mathbf{T a}$ \\
\hline CF8A & 0.05 & 18.3 & 8.2 & Bal. & 1.30 & - & - & - & 0.50 & 0.020 & 0.0060 & - \\
\hline 308L & 0.01 & 20.0 & 10.0 & Bal. & 1.70 & - & 0.10 & - & 0.40 & 0.020 & 0.0100 & - \\
\hline 52M & 0.02 & 29.7 & Bal. & 8.8 & 0.70 & 0.8 & 0.05 & 0.17 & 0.11 & 0.002 & 0.0005 & 0.14 \\
\hline 52MSS & 0.023 & 29.5 & Bal. & 8.8 & 0.31 & 2.5 & 3.50 & 0.18 & 0.11 & 0.004 & 0.0005 & 0.01 \\
\hline
\end{tabular}

After the overlay-welding, the samples were sliced from the welds with an electro-discharged wire cutter in the direction either parallel or normal to the top weld surface. The cut samples were subjected to metallographic preparations for further examinations. Figure 1 is a schematic diagram showing the investigated samples sectioned from the overlays for inspecting the internal cracks. Hot cracks were more likely to be observed on the top weld surface, thus the top surface of sample 1 was examined to find evidence of hot cracks. By contrast, the DDC could be observed in the overlay, which was the 
heat-affected zone (HAZ) of the subsequent passes. After sectioning samples from the overlay weld, the upper surface of sample 2 was subjected to metallographic preparations for DDC observations. Figure $5 c, d$ as well as Figure 6 were the results taken from sample 1. Moreover, sample 2 was used to examine the DDC in the overlay welds, shown in Figure 5e,f.

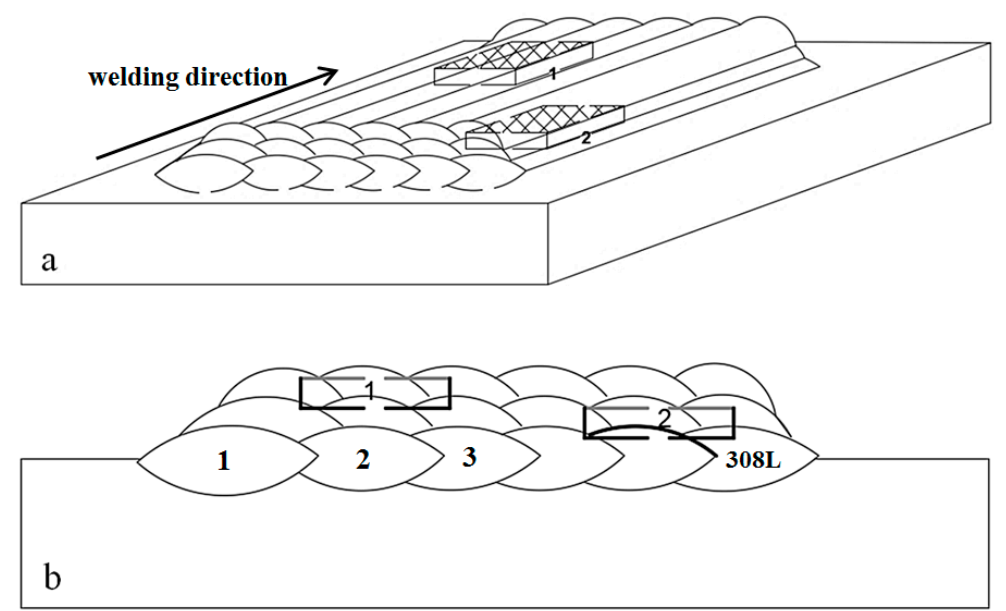

Figure 1. Schematic diagrams showing (a) macroscopic view of overlay weld, (b) the sample 1 for hot cracking and sample 2 for ductility dip cracking (DDC) examinations.

The microstructures of various specimens were observed with an optical microscope (OM) and a scanning electron microscope (SEM). A Mitutoyo MVK-G1500 microhardness tester (Mitutoyo, Kawasaki, Japan) was applied with a load of $300 \mathrm{gf}$ for $15 \mathrm{sec}$ to measure the hardness of different samples. Differential scanning calorimetry (DSC) was applied to measure the liquidus and solidus temperatures of the investigated samples. The chemical compositions of the various phases at the interdendritic boundaries were determined by using either an $\mathrm{X}-\mathrm{Max}^{\mathrm{N}}$ energy-dispersive spectrometer (EDS, Oxford Instruments, Abingdon, UK) or a JXA-8200 electron probe micro-analyzer (EPMA, JEOL, Tokyo, Japan) equipped with the SEM. Moreover, a field emission SEM equipped with a detector of NordlysMax ${ }^{2}$ EBSD (Oxford Instruments, Abingdon, UK) was used to identify the structure of those microconstituents present at the interdendritic boundaries.

\section{Results and Discussion}

\subsection{Macro-Appearance of Overlay Welds}

Figure 2 shows the macro-appearance of overlay welds viewed from the top weld surface. With proper overlap of the weld beads, the overall surface of the overlay welds was quite smooth. Figure 2a,b show the surface morphologies of overlay welds deposited by using 52M and 52MSS fillers directly onto the CF8A substrate. The results indicated that hot cracks were more likely to be seen in the ending craters, especially those of the 52MSS welds. Occasionally, short fine cracks could be found in the 52MSS overlays after metallographic preparations. It was deduced that the ending craters that were concave in shape naturally had low resistance to shrinkage stress, resulting in high hot crack sensitivity. To prevent contamination with harmful elements from the CF8A substrate, 308L filler was deposited first onto the CF8A substrate as the buffer layer, followed by applying Ni-based fillers on the buffer layer. As reported in prior studies, introducing a buffer layer can lower the hot crack susceptibility of overlay welds effectively [18-22]. Figure 2c,d show the surface morphologies of 52M and 52MSS overlays with the 308L buffer layer. With an extra supply of filler metal during the final stage of welding, the concavity of the ending crater was alleviated. The smoother crater profile in the overlay weld was also beneficial in lowering the hot cracking tendency. In fact, only a few surface cracks appeared in the craters of the 52MSS overlay weld. As compared with the overlay welds without 
a buffer layer, the decreased dilution from the CF8A substrate inevitably improved the resistance to hot cracking of the overlay welds.


\section{Welding direction $\downarrow$}

Figure 2. Macro-appearance of overlay welds: (a) 52M, (b) 52MSS without buffer layer; (c) 52M, (d) 52MSS with buffer layer in the as-deposited condition.

Typical cross-sections of the overlay welds are shown in Figure 3. Figure 3a shows the 52M overlay directly deposited on the CF8A substrate. When the feeding speed of 52M filler was $1500 \mathrm{~mm} / \mathrm{min}$, a ripple formed at the bottom of the overlays indicated the dissolution of the CF8A substrate into the $52 \mathrm{M}$ overlays during overlay-welding. A cross-section of the weld with a 308L buffer layer applied prior to the Ni-based fillers is displayed in Figure 3b. The buffer layer was applied at a filler-feeding speed of $1050 \mathrm{~mm} / \mathrm{min}$. Although the overall thickness of the buffer layer was not less than $2 \mathrm{~mm}$, a fluctuation in the thickness of buffer layer at specific sites occurred. A thin buffer layer was associated with the risk of high dilution of the substrate during the subsequent deposition of Ni-based fillers. A macro-view of the overlay weld with the 308L feeding speed increased to $1250 \mathrm{~mm} / \mathrm{min}$ and two layers applied onto the CF8A substrate before the Ni-based overlay was deposited is shown in Figure 3c. Due to the thicker buffer layer, the contamination of the Ni-based overlay by the CF8A substrate was effectively prevented. Moreover, increasing the $52 \mathrm{M}$ feeding speed to $1900 \mathrm{~mm} / \mathrm{min}$ was also accompanied by a decrease in the observable surface cracks of the overlay, especially at the ending craters of the weld (Figure $3 \mathrm{~d}$ ).

\subsection{Microstructural Observations}

Figure 4 presents metallographs showing the microstructures of the overlay welds. The CF8A substrate consisted of about $8 \%$ ferrite, which was in the form of coarse skeleton $\delta$ ferrite dispersed in a $\gamma$ matrix. The microhardnesses of the CF8A substrate, 52M, and 52MSS overlays were about HV (Vickers hardness number) 155,160 , and 175, respectively. The hardness of 52MSS overlay was higher than that of the 52M overlay. The CF8A substrate was softer than the weld overlays. The higher hardness of the 52MSS overlay exhibited greater tensile strength than that of the 52M [25]. When Ni-based fillers were deposited directly on the CF8A substrate, cracks initiated from the interfacial region, regardless of the 
different fillers (Figure 4a,b). As mentioned previously, only a few surface cracks were observed in the ending craters of 52MSS overlay welds if a buffer layer was applied. In addition, top surface cracks were seldom found in the 52M overlay, even without a buffer layer. In the crater regions, the cracks also tended to grow from the Ni-filler/308L interface into the Ni-based overlays if a buffer layer was applied (Figure 4c,d). Thus, the internal cracks in the overlay, which were embedded below the top weld surface, would likely extend to the surface during long-term service.
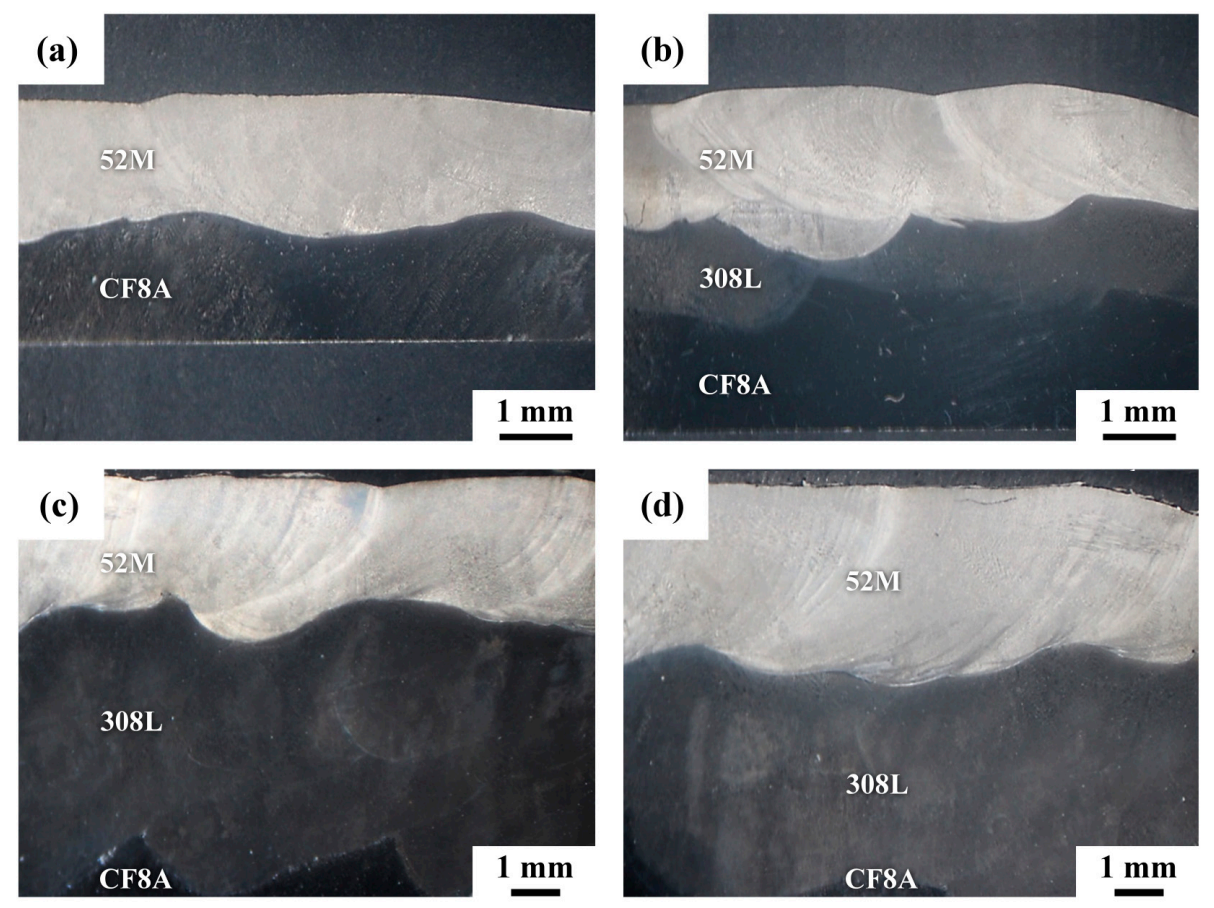

Figure 3. Typical cross-sections of the overlay welds: (a) 52M without buffer layer, (b) 52M with single buffer layer, (c) 52M with double buffer layer, (d) thicker 52M with double buffer layer.
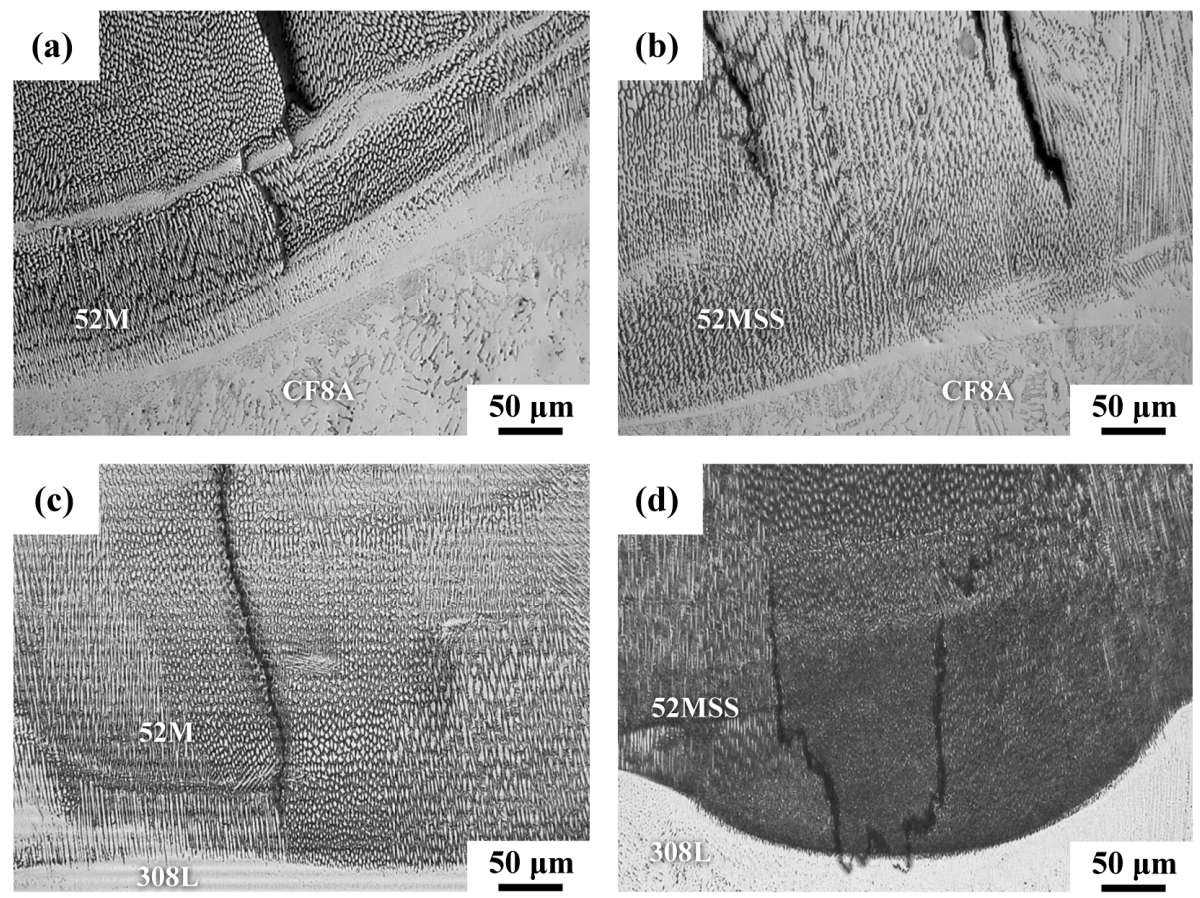

Figure 4. Optical metallographs of distinct overlay welds: (a) 52M, (b) 52MSS without buffer layer; (c) 52M, (d) 52MSS with buffer layer. 
Figure 5 presents photographs showing the detailed microstructures of the various overlay specimens. The optical microstructures of the 52M and 52MSS overlays were very similar, in that they were comprised of cellular dendrites with very fine precipitates distributed along the solidified boundaries (Figure 5a,b). SEM micrographs revealed that the cellular dendrite boundaries consisted of irregular fine precipitates and even some lamellar white phases (Figure $5 c, d$ ). As reported in prior studies, the white phases at the interdendritic boundaries were found to be rich in $\mathrm{Ti}, \mathrm{Nb}$, and $\mathrm{Mo}$ elements [25]. In addition, the grain boundary precipitates in the 52MSS overlay were more numerous and larger than those in the 52M overlay. It was noticed that those white phases in the 52M overlay were more likely in long island-like forms, and some aggregated into irregular morphologies (Figure 5c). By contrast, chain island-like precipitates were found to decorate the solidified boundaries of the 52MSS overlay (Figure 5d). In addition, coarse white phases were in the Chinese embroidery form, which could be related to the eutectic constituents formed during the final stage of solidification. Undoubtedly, the causes of hot cracking of the weld overlays could be associated with those white phases or precipitates at the interdendritic boundaries. As shown in Figure 1b, the top surface of sample 2 was inspected to find DDC. Grain boundary migration in the overlays did occur, as shown in Figure 5e,f. The migrated boundaries in the 52MSS overlay were more tortuous than those in the 52M overlay. The larger number of precipitates at the boundaries of the former than at those of the latter could retard or drag the motion of grain boundaries, resulting in the more tortuous migrated boundaries. After the samples were polished, those migrated boundaries were not observed. With careful section of the sample in the direction parallel to the welding direction, DDC did not occur in either sample under the welding conditions of this study.
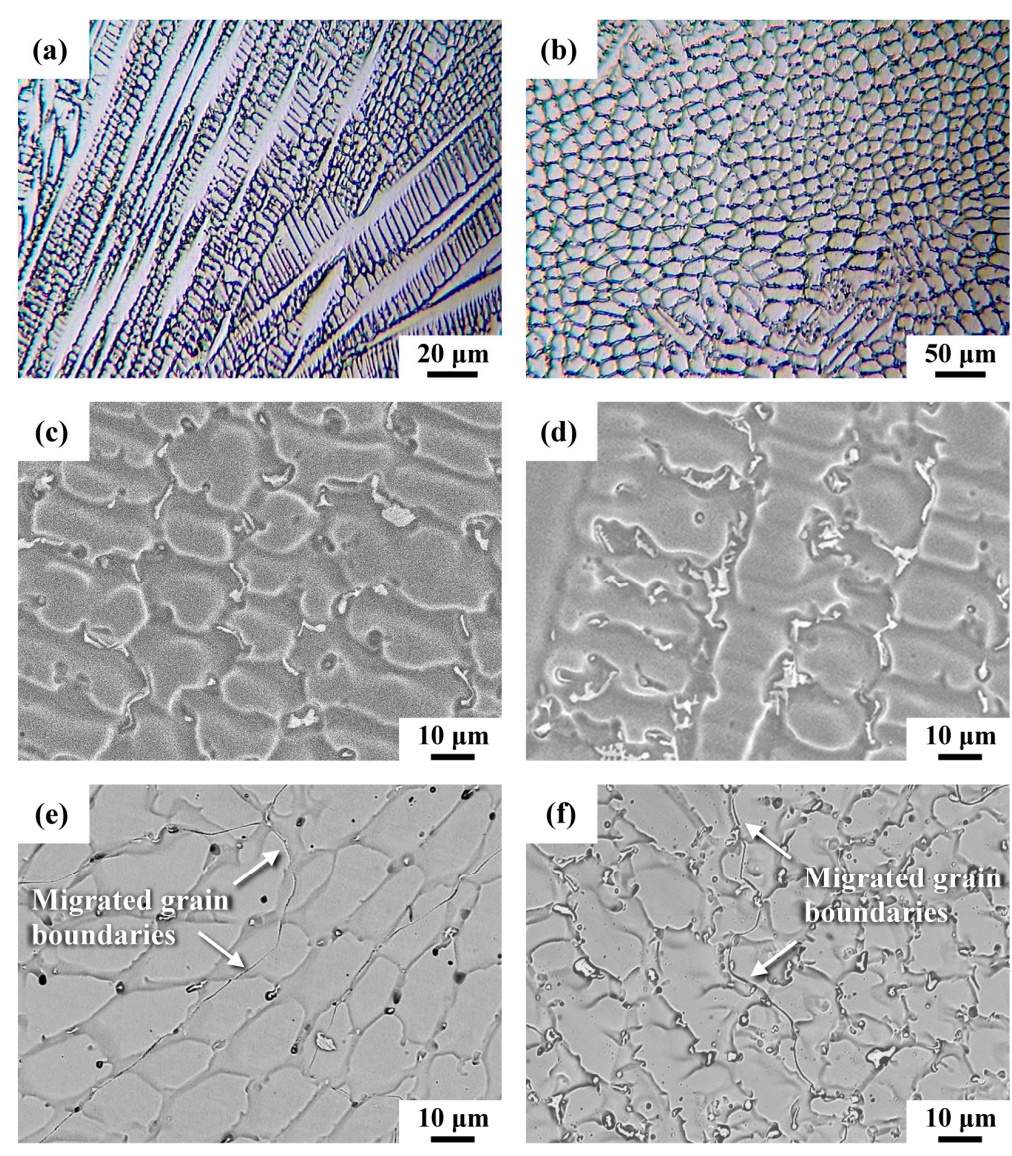

Figure 5. (a,b) Optical micrographs showing the solidified microstructures of 52M overlay oriented parallel or normal to growth direction; (c,d) SEM micrographs of 52M and 52MSS overlays showing the grain boundary microconstituents; (e,f) SEM micrographs of migrated grain boundaries (indicated by the arrows) in the 52M and 52MSS overlays. 


\subsection{Microstructural Identifications}

The fracture features of the internal cracks were investigated to distinguish hot cracking from DDC. The cracks embedded in the overlay were examined after metallographic preparations. Figure 6 shows the internal cracks present in the Ni-based overlays. Inevitably, the internal cracks propagated along the white phases in the 52M (Figure 6a) and 52MSS (Figure 6b). The detailed microstructures at the grain boundaries were chain-island in form and had a lamellar structure (Figure 6c). The appearance of partially open cracks showed that the cracked surface was comprised of numerous droplets decorated with fine precipitates in the 52MSS overlay (Figure 6d). Those precipitates in Figure 6d had nearly the same features as those in Figure 6c. Such findings confirmed that predominant solidification cracking occurred in the Ni-based overlays, particularly in 52MSS. Moreover, the backscattered electron (BSE) image showed that those white precipitates were likely associated with the segregation of heavy alloy elements to the solidified boundaries. Therefore, it was deduced that the lamellar structure on the cracked surface could be related to the eutectic constituents formed during the final stage of solidification.
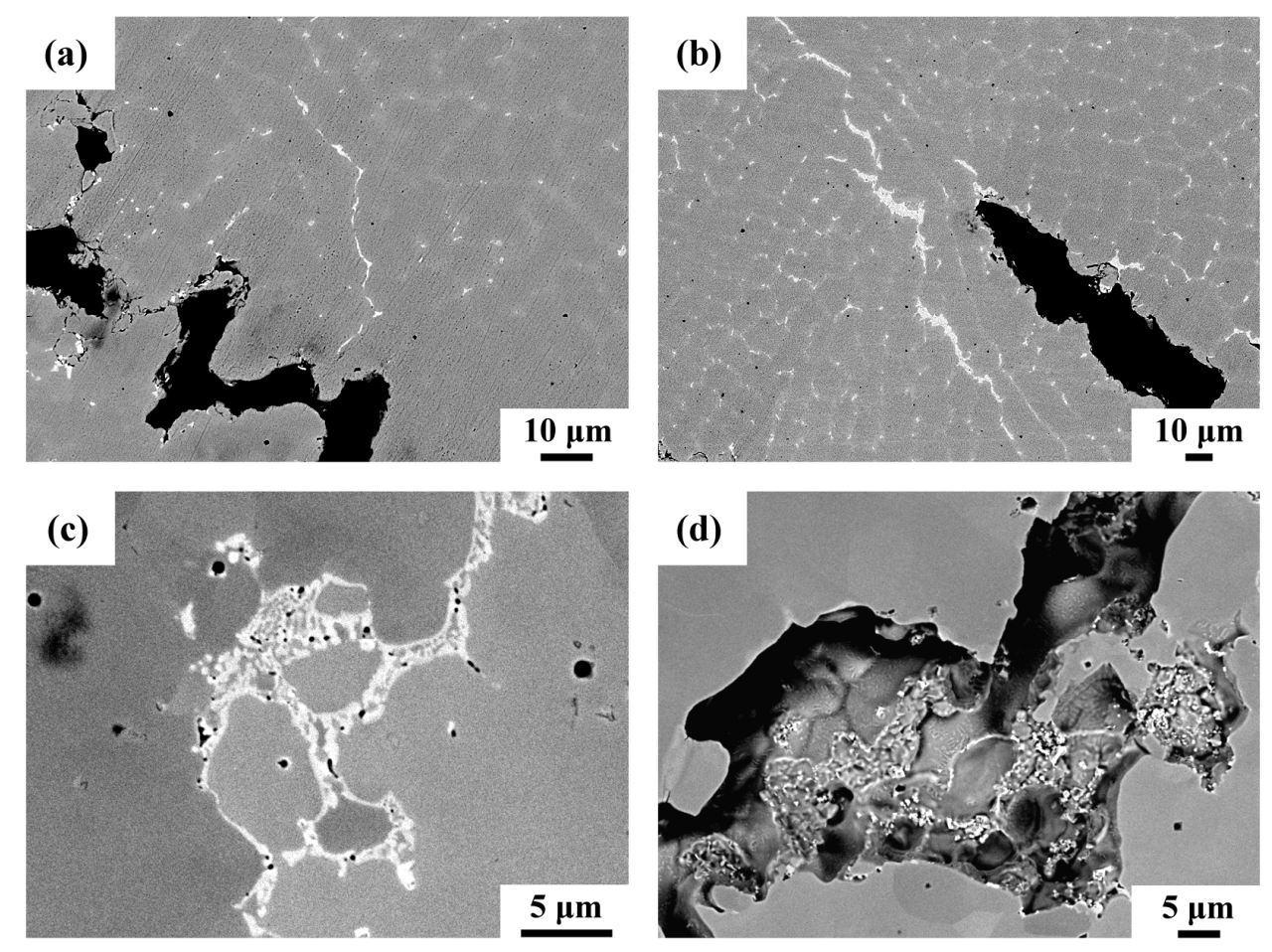

Figure 6. Backscattered electron (BSE) images showing the internal cracks in the (a) 52M, (b) 52MSS, (c) microconstituents in the 52MSS, (d) microconstituents deposited on the cracked 52MSS overlays.

After metallographic preparations, the morphologies of the solidification products were inspected by SEM in BSE image, and the chemical compositions of the white phases in the 52MSS overlay were determined by EPMA. The BSE image and EPMA elemental maps of the white phases in chain islands ahead of the internal cracks in the 52MSS overlay are displayed in Figure 7. The white phases in lamellar form at the grain boundary (Figure 7a) were expected to be eutectic micro-constituents that formed during the final solidification stage of the welding. According to the BSE image contrast (Figure 7a), heavy elements should co-segregate and participate into the final solidification products. According to the composition of the 52MSS filler, the EPMA elemental maps (Figure $7 \mathrm{~b}$ ) indicated that the eutectic colony was lean in $\mathrm{C}, \mathrm{Cr}, \mathrm{Ni}$, and Fe elements, but rich in $\mathrm{Nb}$ and Mo. Those fine precipitates around the major solidification products also showed the same distributions of alloy elements as the coarse ones. The lamellar white phases were low in C content; thus, they likely were unrelated to the eutectic constituents of the $\gamma$-MC (metal carbides) solidification products. 


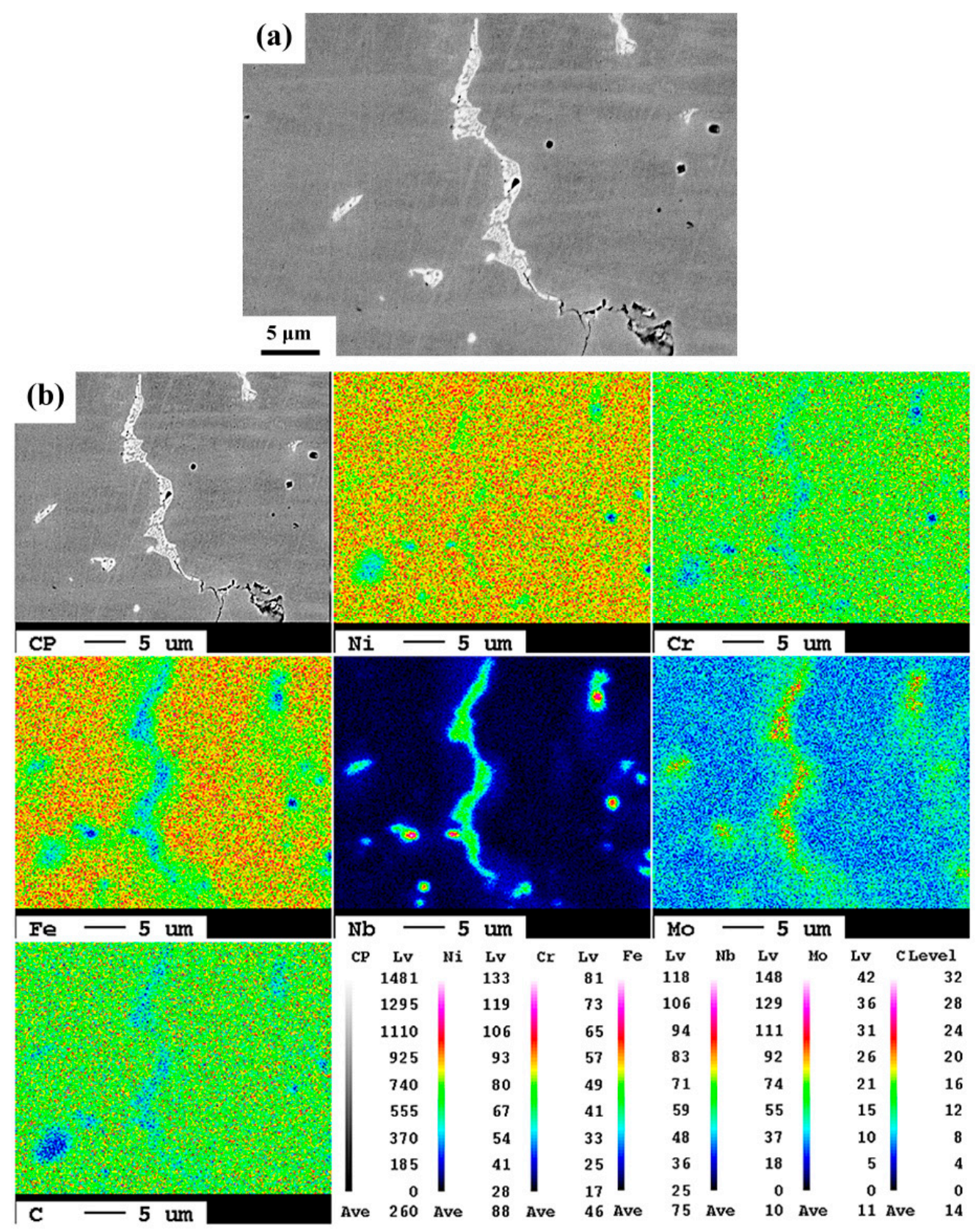

Figure 7. (a) BSE image, (b) electron probe micro-analyzer (EPMA) elemental maps of grain boundary precipitates formed ahead of the crack front in the 52MSS overlay.

The phase constituents of the solidified products at the grain boundaries were identified by EBSD phase mapping, and their compositions were further checked by EPMA, as shown in Figure 8. The EBSD phase map (Figure 8a) confirmed that the lamellar white phases were predominantly $\left(\mathrm{Ni}_{3}(\mathrm{Nb}, \mathrm{Mo})\right)$ mixed with very few $\left(\mathrm{Ni}_{6}(\mathrm{Nb}, \mathrm{Mo})_{7}\right)$ intermetallics. The EPMA elemental maps (Figure $8 \mathrm{~b}$ ) indicated that the eutectic colonies were rich in $\mathrm{Nb}$ and Mo but lacked $\mathrm{Ni}, \mathrm{Fe}, \mathrm{Cr}$, and $\mathrm{C}$. Moreover, $\mathrm{MC}$ (metal carbides) were found occasionally as isolated particles but not in the lamellar structure in the overlays. Therefore, $\gamma-\mathrm{Ni}_{3}(\mathrm{Nb}, \mathrm{Mo})$ intermetallics were the major phases that formed at the grain boundaries during the final solidification stage, which were also responsible for the hot cracking of the overlay welds. Despite their difference in morphology, the grain boundary precipitates in the lamellar form had similar phase constituents. Therefore, it was deduced that the $\gamma-\mathrm{Ni}_{3}(\mathrm{Nb}, \mathrm{Mo})$ eutectics were the major causes of the hot cracking of 52M and 52MSS overlay welds. 

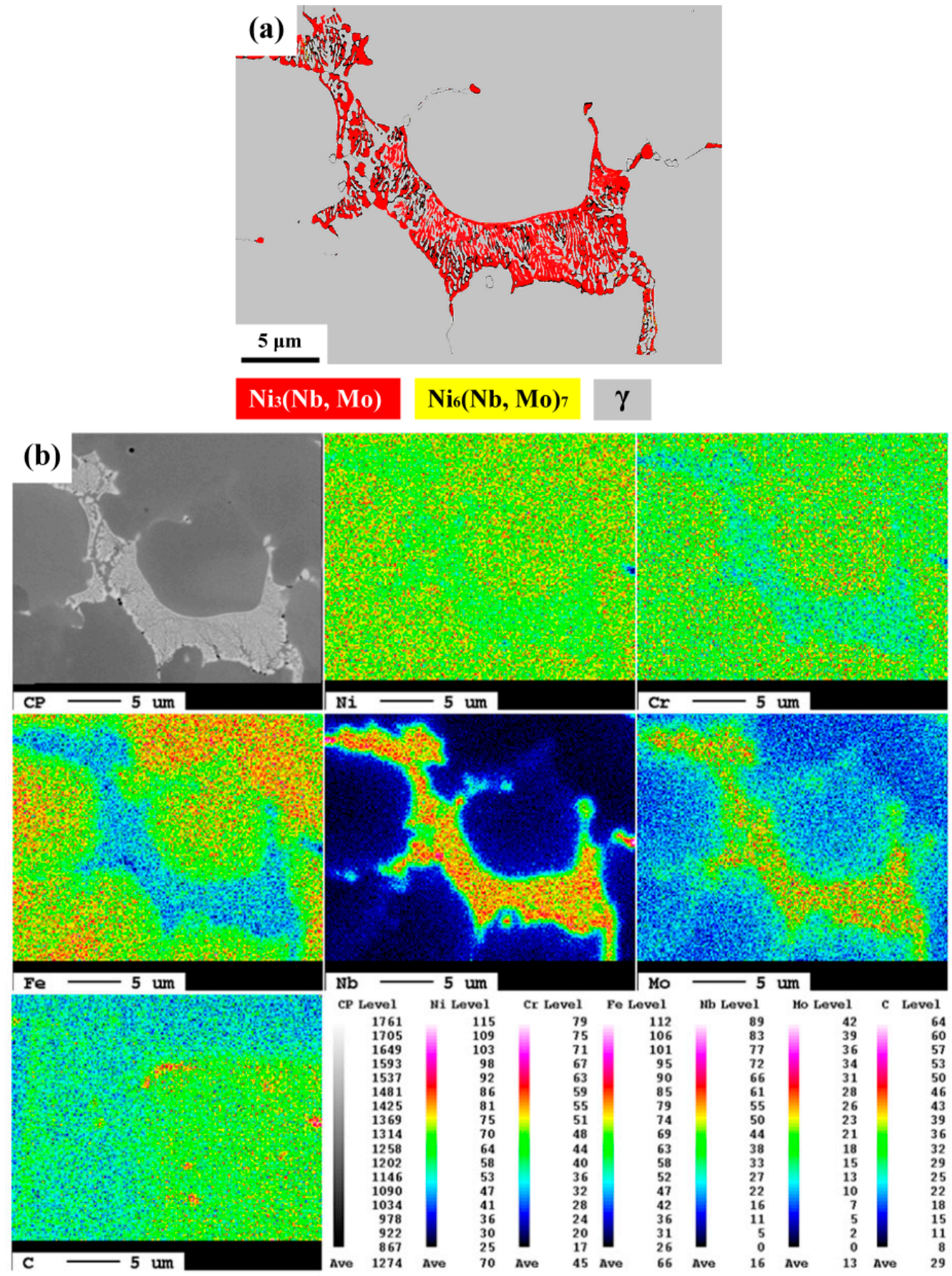

Figure 8. (a) Electron backscatter diffraction (EBSD) phase map, (b) EPMA elemental maps of solidification products in the 52MSS overlay.

\subsection{Hot Crack Features}

SEM fractographs in BSE image of opened microcracks in 52MSS craters and the associated EPMA elemental maps are displayed in Figure 9. After the microcracks were opened, the fractured surface displayed typical columnar features decorated with some terminal solidification products (Figure 9a,b). The coverings on the cracked surface had different morphologies including chain-island, leaf-like, and aligned particles. The separations between cellular dendrites were closely associated with solidification products in the overlay welds. Those terminal solidification products were more likely in lamellar structures, as shown in Figure 9b. The chemical compositions and the elemental distributions of those coverings were determined by EPMA and shown in Figure 9c. The EPMA 
elemental maps showed that those interdendritic precipitates had low $\mathrm{Ni}$, Fe, and $\mathrm{Cr}$ contents but were rich in $\mathrm{Nb}$. It was obvious that those lamellar precipitates did not consist of high $\mathrm{C}$ content. According to the EBSD analysis, it was deduced that the segregation of $\mathrm{Nb}$ to dendrite boundaries of the overlay weld assisted the formation of $\mathrm{Ni}_{3} \mathrm{Nb}$ intermetallics. Therefore, the formation of $\gamma-\mathrm{Ni} 3(\mathrm{Nb}, \mathrm{Mo})$ liquid film at the grain boundaries was responsible for the hot cracking of IN52M and 52MSS overlay welds, particularly for the 52MSS. The $C$ map (Figure 9c) revealed the evidence of segregation of $C$ to interdendritic boundaries. Some $\mathrm{NbC}$ particles and fine carbide particles were found on the fracture surface (Figure 9b). It seemed that $\gamma$-MC eutectics did not dominate the hot cracking of the Ni-base overlays in this study. However, the segregation of $\mathrm{C}$ to the grain boundaries could depress the final solidification temperature, and enhance the hot cracking of the overlay welds.
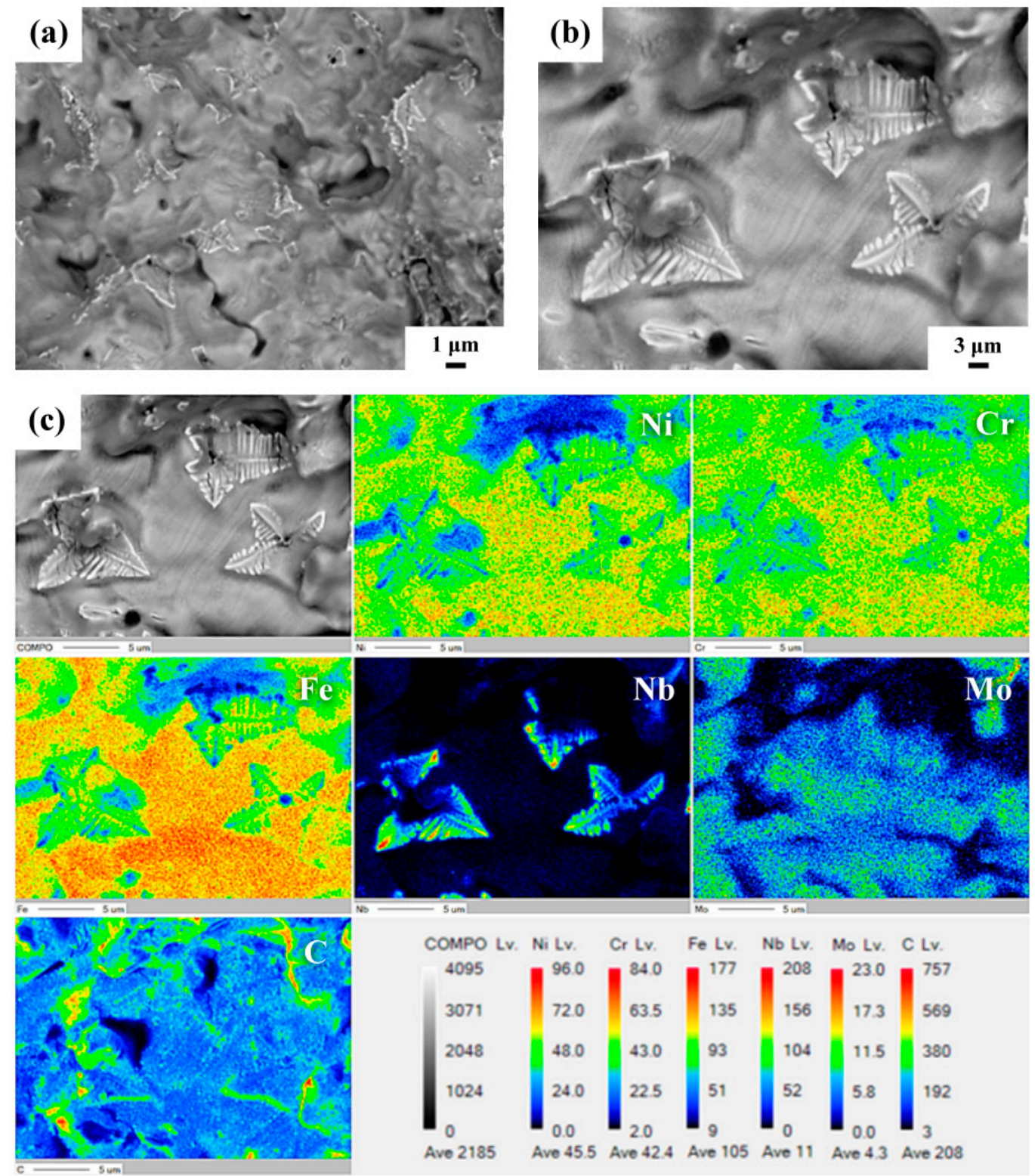

Figure 9. (a,b) Fracture appearance of opened hot crack, (c) EPMA elemental maps of solidification products on the cracked surface in the 52MSS overlay. 


\section{Discussion}

Hot cracks were found to originate in the diluted zone near the weld interface in this work and in prior studies [18,21]. The solidification modes, microstructures, and morphologies of austenitic welds are known to be strongly affected by their compositions and $\mathrm{Ni}, \mathrm{Cr}$ equivalents. To prevent hot cracking during welding, a fully austenitic weld should consist of very low concentration of impurities [36]. A drastic change in composition in the diluted zone around the weld interface occurs [18], leading to a change in solidification mode from the primary ferrite to the primary austenite mode in a dissimilar metal weld. Therefore, those impurities from the substrate were expected to initiate hot cracks at the weld interface. Applying a buffer layer was helpful in reducing the harmful impurities coming from the CF8A substrate to initiate hot cracking. Thin slices were cut parallel to the top surfaces of the overlay welds for more extensive examinations of the hot cracks in the samples with buffer layers in this study. Internal cracks were not seen in the 52M overlay, and few fine short cracks were observed in the 52MSS overlay with a buffer layer. Therefore, applying a buffer layer of sufficient thickness is necessary to prevent hot cracking of 52M and 52MSS overlay welds.

The metallographic examinations of this work confirmed that the hot cracking susceptibility of the 52MSS overlay was higher than that of the 52M overlay [34,35]. Table 2 lists the solidus and liquidus temperatures of different samples determined by DSC. It was found that the solidus temperature of the overlay was lower than that of the filler in each group. This could be related to the segregation and formation of low melting point constituents at the solidified boundaries. The lower $T_{S}$ (solidus temperature) also meant a greater accumulation of shrinkage strain during solidification after welding, which was detrimental to its weldability. Moreover, the results indicated that the solidification temperature range $\left(\Delta T_{L \rightarrow S}\right)$ decreased in the following order: 52MSS overlay $>52 \mathrm{MSS}$ filler $>52 \mathrm{M}$ overlay $>52 \mathrm{M}$ filler $\left(81,57,48\right.$, and $36^{\circ} \mathrm{C}$, respectively). A wider $\Delta T_{L \rightarrow S}$ temperature range of the $52 \mathrm{MSS}$ overlay also implied that it was more susceptible to solidification or hot cracking than other samples were.

Table 2. The solidus and liquidus temperatures of different samples determined by differential scanning calorimetry.

\begin{tabular}{cccc}
\hline \multirow{2}{*}{ Materials } & \multicolumn{3}{c}{ Temperature $\left({ }^{\circ} \mathbf{C}\right)$} \\
\cline { 2 - 4 } & $\boldsymbol{T}_{\boldsymbol{S}}$ & $\boldsymbol{T}_{\boldsymbol{L}}$ & $\boldsymbol{\Delta} \boldsymbol{T}_{\boldsymbol{L} \rightarrow \mathcal{S}}$ \\
\hline 52M filler & 1345 & 1381 & 36 \\
\hline 52MSS filler & 1342 & 1399 & 57 \\
\hline 52M overlay & 1310 & 1358 & 48 \\
\hline 52MSS overlay & 1291 & 1378 & 81 \\
\hline$T_{S}:$ Solidus temperature; $T_{L}:$ Liquidus temperature; $\Delta T_{L \rightarrow S}:$ Solidification temperature range.
\end{tabular}

Liquation cracking of grain boundary precipitates such as gamma prime [37], MC carbides [38], Cr-Mo borides, and intermetallics [39] is responsible for the poor weldability of the Ni-based superalloys. It is reported that two eutectic-type reactions at the terminal stages of solidification, $\mathrm{L} \rightarrow(\mathrm{NbC}-\gamma)$ and $\mathrm{L} \rightarrow($ Laves- $\gamma)$, occur at the interdendritic boundaries during the solidification of $\mathrm{Nb}$-bearing superalloys and IN 625 alloy [40,41]. Those reactions are responsible for the increased susceptibility of $\mathrm{Nb}$-bearing alloys to solidification cracking. In this work, the hot cracking of 52M and 52MSS overlay welds was attributed mainly to the formation of $\gamma-\mathrm{Ni}_{3}(\mathrm{Nb}, \mathrm{Mo})$ eutectics at the boundaries during the terminal stage of solidification. Due to the greater $\mathrm{Nb}$ and $\mathrm{Mo}$ contents in the 52MSS overlay, coarser and greater amounts of microconstituents were formed at the interdendritic boundaries, thus, the hot cracking susceptibility of the 52MSS overlay was naturally higher than that of the 52M overlay. Moreover, The $\mathrm{C}$ maps showed the segregation of $\mathrm{C}$ and the formation of fine carbides on the cracked surface. The segregation of $C$ to the grain boundaries could depress the final solidification temperature, and enhance the hot cracking of the overlay welds. 


\section{Summary}

In this study, gas tungsten arc welding process in multiple passes was applied to deposit IN52M and 52MSS onto CF8A stainless steel. The susceptibility to hot cracking and ductility dip cracking (DDC) of the IN52M and IN52MSS overlay welds was investigated. The hot cracking tendency of the overlay welds was associated with the presence of low-melting microconstituents at the interdendritic boundaries. The formation of $\gamma-\left(\mathrm{Ni}_{3}(\mathrm{Nb}, \mathrm{Mo})\right)$ eutectics was responsible predominantly for the hot cracking of the 52M and 52MSS overlays, especially that of the 52MSS overlay. The solidification temperature range $\left(\Delta T_{L \rightarrow S}\right)$ decreased in the following order: 52MSS overlay $>52 \mathrm{MSS}$ filler $>52 \mathrm{M}$ overlay $>52 \mathrm{M}$ filler $\left(81,57,48\right.$, and $36^{\circ} \mathrm{C}$, respectively). The results also confirmed that the $52 \mathrm{MSS}$ overlay was more susceptible to solidification or hot cracking than the 52M overlay. Migrated grain boundaries were observed in the 52M and 52MSS overlays, but they did not induce DDC in this study.

Author Contributions: L.-W.T. and S.-L.J. organized this study. M.-Y.C., T.-J.W., and T.-C.C. worked together, and performed all the experimental tests. All authors were involved in completing the manuscript.

Funding: This research was funded by the Institute of Nuclear Energy Research, Division of Nuclear Fuels and Materials, Taiwan (Contract No. NL1070386).

Conflicts of Interest: The authors declare no conflict of interest.

\section{References}

1. Park, J.-H.; Chopra, O.K.; Natesan, K.; Shack, W.J.; Cullen, W.H., Jr. Boric acid corrosion of light water reactor pressure vessel head materials. In Proceedings of the 12th International Conference on Environmentally Degradation of Materials in Nuclear systems-Water Reactors, Pittsburgh, PA, USA, 14-18 August 2005; pp. 459-468.

2. Bamford, W.; Hall, J. A review of alloy 600 cracking in operating nuclear plants including alloy 82 and 182 weld behavior. In Proceedings of the 12th International Conference on Nuclear Engineering, New York, NY, USA, 25-29 April 2004; pp. 131-139.

3. Scott, P.M.; Combrade, P. On the mechanism of stress corrosion crack initiation and growth in alloy 600 exposed to PWR primary water. In Proceedings of the 11th International Conference on Environmental Degradation of Materials in Nuclear Power System-Water Reactors, La Grange Park, IL, USA, 10-14 August 2003; pp. 29-38.

4. Jenssen, A.; Norrgaard, K.; Lagerstroem, J.; Embring, G.; Tice, D.R. Assessment of cracking in dissimilar metal welds. In Proceedings of the 10th International Conference on Environmentally Degradation of Materials in Nuclear systems - Water Reactors; NACE International, Houston, TX, USA, 5-9 August 2001.

5. King, C.; Frederick, G. Technical basis for Preemptive Weld Overlays for Alloy 82/182 Butt Welds in PWRs (MRP-169) Revision 1; EPRI: Palo Alto, CA, USA, 2008.

6. Xie, Y.; Wu, Y.; Burns, J.; Zhang, J. Characterization of stress corrosion cracks in Ni-based weld alloys 52, 52M and 152 grown in high-temperature water. Mater. Charact. 2016, 112, 87-97. [CrossRef]

7. Li, G.; Zhang, M.; Huang, J.; Sun, Z.; Wu, Y. A comparative study on microstructure and properties of Inconel 52M overlays deposited by laser beam and GTA cladding. Int. J. Adv. Manuf. Technol. 2015, 81, 103-112. [CrossRef]

8. Song, T.K.; Bae, H.R.; Kim, Y.J.; Lee, K.S. Numerical investigation on welding residual stresses in a PWR pressurizer safety/relief nozzle. Fatigue Fract. Eng. Mater. Struct. 2010, 33, 689-702. [CrossRef]

9. Huang, C.C.; Liu, R.F. Structural integrity analyses for preemptive weld overlay on the dissimilar metal weld of a pressurizer nozzle. Int. J. Press. Vessel. Pip. 2012, 90-91, 77-83. [CrossRef]

10. Fink, C.; Zinke, M.; Keil, D. Evaluation of hot cracking susceptibility of nickel-based alloys by the PVR test. Weld. World 2012, 56, 37-43. [CrossRef]

11. Chen, T.C.; Cheng, Y.H.; Tsay, L.W.; Shiue, R.K. Effects of grain boundary microconstituents on heat-affected zone cracks in a Mar-M004 weldment. Metals 2018, 8, 201. [CrossRef]

12. Cheng, Y.H.; Chen, J.T.; Shiue, R.K.; Tsay, L.W. The evolution of cast microstructures on the HAZ liquation cracking of Mar-M004 weld. Metals 2018, 8, 35. [CrossRef]

13. Chen, K.C.; Chen, T.C.; Shiue, R.K.; Tsay, L.W. Liquation cracking in the heat-affected zone of IN738 superalloy weld. Metals 2018, 8, 387. [CrossRef] 
14. Angella, G.; Barbieri, G.; Donnini, R.; Montanari, R.; Richetta, M.; Varone, A. Electron beam welding of IN792 DS: effects of pass speed and PWHT on microstructure and hardness. Materials 2017, 10, 1033. [CrossRef]

15. Li, Q.; Lin, X.; Wang, X.; Yang, H.; Song, M.; Huang, W. Research on the grain boundary liquation mechanism in heat affected zones of laser forming repaired K465 nickel-based superalloy. Metals 2016, 6, 64. [CrossRef]

16. Lippold, J.C.; Kiser, S.D.; DuPont, J.N. Welding Metallurgy and Weldability of Nickel-Base Alloys; John Wiley \& Sons: Hoboken, NJ, USA, 2011.

17. Hänninen, H.; Brederholm, A.; Saukkonen, T. Hot Cracking Susceptibility of Ni-base Alloy Dissimilar Metal Welds, Hot Cracking Phenomena in Welds II; Springer: Berlin, Heidelberg, 2008; pp. 171-191.

18. Chu, H.A.; Young, M.C.; Chu, H.C.; Tsay, L.W.; Chen, C. Hot cracking susceptibility of Alloy 52M weld overlays onto CF8 stainless steel. J. Nucl. Mater. 2013, 433, 419-423. [CrossRef]

19. Shih, Y.-J. Mitigation of hot cracking of alloy 52M overlay on cast stainless steel CF8A. Sci. Technol. Weld. Join. 2013, 18, 566-572. [CrossRef]

20. Lin, C.-M. Relationships between microstructures and properties of buffer layer with Inconel $52 \mathrm{M}$ clad on AISI 316L stainless steel by GTAW processing. Surf. Coatings Technol. 2013, 228, 234-241. [CrossRef]

21. Chu, H.A.; Young, M.C.; Chu, H.C.; Tsay, L.W.; Chen, C. The effect of Nb and S segregation on the solidification cracking of alloy 52M weld overlay on CF8 stainless steel. J. Mater. Eng. Perform. 2014, 23, 967-974. [CrossRef]

22. Ko, G.; Seo, K.M.; Kim, H.J.; Hong, H. Characteristics of hot cracking in dissimilar joint of A690 overlay and stainless steel clad. Weld. World 2017, 61, 945-953. [CrossRef]

23. Tsai, K.-C.; Jeng, S.-L. A feasibility study of applying SS 307Si buffer layer for mitigating the hot cracking of Ni-based weld overlay. J. Mater. Eng. Perform. 2017, 26, 3698-3709. [CrossRef]

24. Li, G.; Lu, X.; Zhu, X.; Huang, J.; Liu, L.; Wu, Y. The segregation and liquation crackings in the HAZ of multipass laser-welded joints for nuclear power plants. J. Mater. Eng. Perform. 2017, 26, 4083-4091. [CrossRef]

25. Jeng, S.-L.; Chang, Y.-H. The influence of $\mathrm{Nb}$ and Mo on the microstructure and mechanical properties of Ni-Cr-Fe GTAW welds. Mater. Sci. Eng. A 2012, 555, 1-12. [CrossRef]

26. Zhang, X.; Li, D.-Z.; Li, Y.-Y.; Lu, S.-P. Effect of Nb and Mo on the microstructure, mechanical properties and ductility-dip cracking of Ni-Cr-Fe weld metals. Acta Metall. Sin. English Lett. 2016, 29, 928-939. [CrossRef]

27. Hope, A.T.; Lippold, J.C. Development and testing of a high-chromium, Ni-based filler metal resistant to ductility dip cracking and solidification cracking. Weld. World 2017, 61, 325-332. [CrossRef]

28. Ramirez, A.J.; Lippold, J.C. High temperature behavior of Ni-base weld metal: Part I. Ductility and microstructural characterization. Mater. Sci. Eng. A 2004, 380, 259-271. [CrossRef]

29. Ramirez, A.J.; Lippold, J.C. High temperature behavior of Ni-base weld metal: Part II - Insight into the mechanism for ductility dip cracking. Mater. Sci. Eng. A 2004, 380, 245-258. [CrossRef]

30. Ramirez, A.J.; Sowards, J.W.; Lippold, J.C. Improving the ductility-dip cracking resistance of Ni-base alloys. J. Mater. Process. Technol. 2006, 179, 212-218. [CrossRef]

31. Chen, J.Q.; Lu, H.; Cui, W.; Chen, J.M.; Huang, Y.F. Effect of grain boundary behaviour on ductility dip cracking mechanism. Mater. Sci. Technol. 2014, 30, 1189-1196. [CrossRef]

32. Chen, J.Q.; Lu, H.; Yu, C.; Chen, J.M.; Zhang, M.L. Ductility dip cracking mechanism of Ni-Cr-Fe alloy based on grain boundary energy. Sci. Technol. Weld. Join. 2013, 18, 346-353. [CrossRef]

33. Wu, W.T.; Tsai, C.H. Hot cracking susceptibility of fillers 52 And 82 in Alloy 690 welding. Metall. Mater. Trans. A 1999, 30A, 417426. [CrossRef]

34. McCracken, S.L.; Alexandrov, B.T.; Lippold, J.C.; Sowards, J.W.; Hope, A.T. Hot cracking study of high chromium nickel-base weld filler metal 52MSS (ERNiCrFe-13) for nuclear applications. In Proceedings of the ASME 2010 Pressure Vessels \& Piping Division Conference, Bellevue, DC, USA, 18-22 July 2010.

35. Yushchenko, K.; Savchenko, V.; Chervyakov, N.; Zvyagintseva, A.; Guyot, E. Comparative hot cracking evaluation of welded joints of alloy 690 using filler metals Inconel 52 And 52 MSS. Weld. World 2011, 55, 28-35. [CrossRef]

36. Brooks, J.A.; Lambert, F.J.J. The effects of phosphorus sulfur and ferrite content on weld cracking of type 309 stainless steel. Weld. J. 1978, 57, 139-143.

37. Ojo, O.A.; Richards, N.L.; Chaturvedi, M.C. Contribution of constitutional liquation of gamma prime precipitate to weld HAZ cracking of cast Inconel 738 superalloy. Scr. Mater. 2004, 50, 641-646. [CrossRef]

38. Ojo, O.A.; Chaturvedi, M.C. Liquation microfissuring in the weld heat-affected zone of an overaged precipitation-hardened nickel-base superalloy. Metall. Mater. Trans. A 2007, 38, 356-369. [CrossRef] 
39. Montazeri, M.; Ghaini, F.M. The liquation cracking behavior of IN738LC superalloy during low power Nd:YAG pulsed laser welding. Mater. Charact. 2012, 67, 65-73. [CrossRef]

40. Dupont, J.N.; Robino, C.V.; Michael, J.R.; Notis, M.R.; Marder, A.R. Solidification of Nb-bearing Superalloys: Part I. Reaction Sequences. Metall. Mater. Trans. A 1998, 29, 27852796. [CrossRef]

41. Cieslak, M.J. The Welding and Solidification Metallurgy of Alloy 625. Weld. J. 1991, 70, 49-56.

(C) 2019 by the authors. Licensee MDPI, Basel, Switzerland. This article is an open access article distributed under the terms and conditions of the Creative Commons Attribution (CC BY) license (http://creativecommons.org/licenses/by/4.0/). 